\title{
IMPLEMENTASI STRATEGI PEMBELAJARAN PRODI PENDIDIKAN BAHASA ARAB IAIN SAMARINDA 2018
}

\author{
Edy Murdani Z \\ Dosen, Institut Agama Islam Negeri Samarinda
}

\begin{abstract}
Abstrak
This study aims to explore information about the implementation of learning strategy of Arabic education program IAIN Samarinda, the object of this study are lecturers who teach on Arabic education study program that is determined by using purposive sampling, in this study, researchers used interview techniques, observation and documentation, while the research desainused is a qualitative approach with the result of a description that aims to find the pattern of information obtained in the field. In this case, the result of the research is (1) Impelementation of learning strategy in IAIN Samarinda Arabic study program runs well which is normative implementation, it is shown by the implementation of learning that has been done by the lecturer of course runs according to its function, such as preparing syllabus and learning tools, using strategies and techniques in teaching, and evaluating at the end of the course. (2) The strategy used in learning in IAIN Samarinda Arabic education program is active learning for speaking skill, cooperative learning for skill, qowaid wa tarjamah for learning element of language of nahwu, shorof and tarjamah, and for reading skill is qiraah shomitah and jahriyah, drill and awlawiyat for writing skills. (3) Factors supporting the implementation are: a. Able to prepare instructional devices at each meeting b. Pengampu determine appropriate strategies and techniques in adjusting teaching materials c. The availability of learning media well (4) The inhibiting factor of the implementation is the learning is a. Qualification of students, so the implementation of the strategy must be really on target and adjust the cognitive level of students b. Distribution of courses not all speak Arabic.
\end{abstract}

Keywords: learning strategy, active learning, drill method.

\section{A. Pendahuluan}

Proses pengajaran adalah proses yang tidak mudah untuk diterapkan, karena ada rangkaian-rangkaian kegiatan yang harus dipenuhi, diantaranya 
Edy Murdani Z: Implementasi Strategi Pembelajaran Prodi Pendidikan Bahasa Arab IAIN Samarinda 2018

adalah tahap persiapan, tahap pengajaran dan evaluasi ${ }^{1}$. Di dalam tahapan tersebut tentunya, pengajar harus melihat dengan luas dan teliti, baik materi ajar, siswa yang diajar, strategi, media dan lain sebagainya agar tujuan dari pengajaran dapat tercapai. Salah satu yang penting dalam hal ini adalah strategi pembelajaran, ia dapat diartikan sebagai rencana dan cara-cara membawakan pengajaran agar segala prinsip dasar dapat terlaksana dan segala tujuan pembelajaran dapat dicapai secara efektif. Cara-cara membawakan pengajaran itu merupakan pola dan urutan umum perbuatan guru dan murid dalam perwujudan kegiatan pembelajaran.

Strategi pembelajaran berarti cara dan seni untuk menggunakan semua sumber belajar dalam upaya membelajarkan siswa. Sebagai suatu cara, strategi pembelajaran dikembangkan dengan kaidah-kaidah tertentu sehingga membentuk suatu bidang pengetahuan tersendiri. Sedangkan sebagai suatu seni, strategi pembelajaran kadang-kadang secara implisit dimiliki oleh seseorang tanpa pernah belajar secara formal tentang ilmu strategi pembelajaran.Strategi pembelajaran digunakan untuk mempermudah proses pembelajaran sehingga dapat mencapai hasil yang optimal. Strategi pembelajaran sebagai perencanaan yang berisi tentang rangkaian kegiatan yang didesain untuk mencapai tujuan pendidikan tertentu ${ }^{2}$. Dari pengertian tersebut, strategi pembelajaran merupakan rencana tindakan termasuk penggunaan metode dan pemanfaatan berbagai sumber daya/kekuatan dalam pembelajaran, selain itu strategi disusun untuk mencapai tujuan tertentu. Oleh karena itu, sebelum menentukan strategi, perlu merumuskan tujuan yang jelas dan dapat diukur keberhasilannya.

Telah diketahui bahwa Bahasa Arab adalah bahasa utama dalam kelompok bahasa Semit yang oleh sementara orang dianggap sebagai bahasa sejarah tertua. Sejarah menunjukan bahasa Arab telah ada sejak sebelum

1 حسن شحاتة , تعليم اللغة العربية بين النطرية و التطبيق( دار المصرية البنانية 1993 ,ص ص 9

${ }^{2}$ Strategi Pembelajaran dan pemilihannya, (Direktorat tenaga kependidikan departemen Pendidikan Nasional 2008), h. 3.

Jurnal Ilmiah Al QALAM, Vol. 12, No. 2, Juli-Desember 2018 
Edy Murdani Z: Implementasi Strategi Pembelajaran Prodi Pendidikan Bahasa Arab IAIN Samarinda 2018

kedatangan Islam, dan setelah Islam datang maka bahasa Arab semakin berada diposisi yang penting ${ }^{3}$.

Pembelajaran adalah proses interaksi peserta didik dengan pendidik dan sumber belajar pada suatu lingkungan belajar. Pembelajaran merupakan bantuan yang diberikan pendidik agar dapat terjadi proses pemerolehan ilmu dan pengetahuan, penguasaan kemahiran dan tabiat, serta pembentukan sikap dan kepercayaan pada peserta didik. Dengan kata lain, pembelajaran adalah proses untuk membantu peserta didik agar dapat belajar dengan baik. Proses pembelajaran dialami sepanjang hayat seorang manusia serta dapat berlaku di manapun dan kapanpun. Saat ini bahasa Arab merupakan salah satu bahasa yang banyak digunakan didunia terutama dinegara-negara Islam. Sejarah mencatat bahwa bahasa Arab mulai menyebar ke luar jazirah Arabia sejak abad ke-1 $\mathrm{H}$ atau abad ke-7 M, karena bahasa Arab selalu terbawa kemanapun Islam terbang. ${ }^{4}$ Hal ini karena bahasa Arab sanga teratkaitanya dengan berbagai bentuk peribadatan dalam Islam disamping kedudukannya sebagai bahasa kitab suci Alquran. Bahasa Arab memiliki nilai sastra yang sangat tinggi yang mengagumkan setiap manusia, sehingga Allah memilih bahasa Arab sebagai bahasa kitab suci Alquran, begitu juga Nabi Muhammad SAW yang merupakan Nabi pilihan diturunkan ditengah-tengah bangsa Arab, suatu bangsa yang menggunakan bahasa Arab sebagai bahasa komunikasi, sehingga Hadits-Hadits Nabi yang merupakan penjelasan dari ayat-ayat Al-Qur'an yang masih global juga ditulis dalam bahasa Arab. Hal ini menjadikan kedudukan bahasa Arab tidak hanya sebagai bahasa untuk berkomunikasi dengan sesama manusia, namun juga sebagai alat untuk berkomunikasi dengan Allah SWT seperti dalam sholat dan ibadah-ibadah lainnya. Selain itu bahasa Arab juga telah digunakan sebagai bahasa ilmu pengetahuan dan telah dijadikan sebagai bahasa resmi internasional. Banyak buku-buku ilmu 2004), h. 16.

${ }^{3}$ As'aril Muhajir, Psikologi Belajar Bahasa Arab (Jakarta: Bina Ilmu,

${ }^{4}$ Ahmad Fuad Efendi, Metodologi Pengajaran Bahasa Arab (Malang: Misykat,2005), h. 19.

Jurnal Ilmiah Al QALAM, Vol. 12, No. 2, Juli-Desember 2018 
Edy Murdani Z: Implementasi Strategi Pembelajaran Prodi Pendidikan Bahasa Arab IAIN Samarinda 2018

pengetahuan dan teknologi yang ditulis dalam bahasa Arab. Dengan demikian tanpa mampu memahami bahasa Arab sudah barang tentu mengurangi kualitas keilmuan seseorang. Sehingga bahasa Arab tidak hanya dipelajari oleh orang Islam saja, namun banyak cendekiawan non muslim yang berbondong-bondong mempelajari bahasa Arab untuk menambah dan memperluas wawasan. Untuk itulah bahasa Arab banyak diajarkan di sekolahsekolah, terutama di sekolah-sekolah Islam sebagai pelajaran pokok. Namun perlu diketahui bahwa belajar bahasa Arab berbeda dengan belajar bahasa ibu, oleh karena itu prinsip dasar pengajarannya harus berbeda, baik menyangkut metode, materi maupun proses pelaksanaan pengajarannya. Bidang keterampilan pada penguasaan bahasa Arab meliputi 4 keterampilan yaitu keterampilan mendengar, keterampilan berbicara, keterampilan membaca dan keterampilan menulis. Pada dasarnya setiap anak manusia mempunyai kemampuan untuk menguasai setiap bahasa, walaupun dalam kadar dan dorongan yang berbeda. Baik perbedaan tujuan pengajaran yang ingin dicapai, kemampuan dasar yang dimiliki, maupun motivasi yang ada di dalam diri dan minat serta ketekunanya. Tujuan pengajaran bahasa itu merupakan tujuan yang hidup yaitu sebagai alat komunikasi untuk mencapai sesuatu yang diinginkan dalam hidupnya, oleh karena itu motivasi belajarnyapun sangat tinggi. Sementara itu belajar bahasa asing seperti bahasa Arab bagi non Arab pada umumnya mempunyai tujuan sebagai alat komunikasi dan ilmu pengetahuan dan kebudayaan. Mengutip pernyataan dari Enok Maryani, Husin juga menjelaskan bahwa antara bahasa dan budaya terdapat keterkaitan yang sangat erat, sehingga bahasa bisa dianggap sebagai salah satu alat (media) yang sangat penting dalam mempelajari warisan kebudayaan. ${ }^{5}$

Dewasa ini kegiatan pembelajaran di setiap jenjang pendidikan harus dikembangkan sesuai dengan abad ini, sehingga setiap dosen dituntut untuk memiliki pemahaman yang tinggi terhadap pendekatan pembelajaran, strategi

\footnotetext{
${ }^{5}$ Husin Husin dan Hatmiati Hatmiati, "Budaya Dalam Penerjemahan Bahasa," Al-Mi'yar, 2, 1 (2018). h. 40.
}

Jurnal Ilmiah Al QALAM, Vol. 12, No. 2, Juli-Desember 2018 
Edy Murdani Z: Implementasi Strategi Pembelajaran Prodi Pendidikan Bahasa Arab IAIN Samarinda 2018

pembelajaran dan metode pembelajaran. Hal ini sangat penting, dikarenakan dosen merupakan perencana utama dalam suatu kegiatan pembelajaran.

Berdasarkan hal tersebut, maka dalam dalam penelitian ini akan dibahas tentang Implementasi Strategi Pembelajaran Program Studi Pendidikan Bahasa Arab IAIN Samarinda 2018.

\section{B. Metode Penelitian}

1. Desain, Sumber Data

Penelitan ini dilaksanakan di IAIN Samarinda, pada fakultas tarbiyah dan ilmu keguruan yang terletak di Kampus II IAIN Samarinda Seberang, adapun waktu pelaksanaan penelitian ini, bermula sejak 13 Maret 2018 sampai 31 Mei 2018

Desain penelitian yang digunakan adalah penelitian deskriptif, yaitu penelitian yang sifatnya menjelaskan situasi atau kejadian-kejadian tertentukan berusaha untuk memutuskan pemecahan masalah yang ada berdasarkan data-data. ${ }^{6}$ Penelitian ini dilakukan dengan cara membuat deskripsi permasalahan yang telah diidentifikasi. Di samping memberikan gambaran atau deskripsi yang sistematis, penilaian yang dilakukan juga untuk mempermudah dalam menjawab masalah-masalah yang terdapat dalam fokus penelitian. $^{7}$

Sumber data atau subyek penelitian dalam kajian ini menitik beratkan pada sumber data pada wawancara, angket, dokumentasi dan observasi. Sumber data tersebut berupa berbagai data baik dari wawancara maupun dokumentasi tertulis dan tidak tertulis terkait dengan upaya para dosen dalam mengimplementasikan strategi pembelajaran di prodi pendididikan bahasa Arab IAIN samarinda.

\footnotetext{
${ }^{6}$ Cholid Narbuko, Abu Ahmadi, Metodologi Penelitian, (Jakarta: PT Bumi Aksara, 2003), h. 44.

${ }^{7}$ W. Surakhmad, Pengantar Penelitian Ilmiah: Dasar Metode Teknik, (Bandung: Tarsito, 1990), h. 143
}

Jurnal Ilmiah Al QALAM, Vol. 12, No. 2, Juli-Desember 2018 
Edy Murdani Z: Implementasi Strategi Pembelajaran Prodi Pendidikan Bahasa Arab IAIN Samarinda 2018

Jenis data yang diperlukan dalam laporan penelitian ini diklasifikasikan menjadi data yang sifatnya primer adalah data yang langsung diambil dari pelaksana kegiatan pembelajaran yaitu para dosen pengajar.Data berikutnya adalah data sekunder berupa berbagai referensi dan hasil penelitian, yakni berupa berbagai rujukan yang mengkaji tentang sumber belajar, pengelolaan lembaga pendidikan, dan Kegiatan Pembelajaran, baik secara teori maupun hasil penelitian lapangan. Antara lain, buku yang memaparkan tentang dinamika pengelolaan lembaga pendidikan, dan sumber belajar. Sedangkan data tertiernya merupakan berbagai bahan yang memberikan petunjuk maupun penjelasan terhadap data primer dan sekunder, misalnya informasi penunjang, kamus, dan ensiklopedia.

2. Teknik Pengumpulan Data

a) Dokumentasi

Cara ini adalah dengan mendokumentasikan segala hal yang menjadi data untuk kajian penelitian. Suharsimi Arikunto menegaskan dokumentasi (dokumenter) dimaknai dengan peneliti melihat serta menyelidiki benda-benda tertulis seperti buku-buku, majalah, dokumen, peraturan-peraturan, jurnal dan sebagainya. ${ }^{8}$.

b) Observasi

Sutrisno Hadi mendefinisikan observasi sebagai pengamatan dan pencatatan dengan sistematik fenomena-fenomena yang diselidiki. ${ }^{9}$ Dengan observasi ini peneliti mengamati hal-ihwal yang telah terjadi sepanjang proses pembelajaran berlangsung.

\footnotetext{
${ }^{8}$ Suharsimi Arikunto,Prosedur Penelitian Suatu Pendekatan Praktik (Jakarta: Rineka Cipta, 1993), h.131.

${ }^{9}$ Sutrisno Hadi, Metodologi Research (Yogyakarta: Fak. Psikologi UGM, 1985), h. 136.
}

Jurnal Ilmiah Al QALAM, Vol. 12, No. 2, Juli-Desember 2018 
Edy Murdani Z: Implementasi Strategi Pembelajaran Prodi Pendidikan Bahasa Arab IAIN Samarinda 2018

c) Wawancara (Interview)

Arief Furqon mengartikan wawancara Sebagai suatu proses tanya jawab lisan, dalam makna dua orang atau lebih berhadap-hadapan secara fisik, yang satu dapat melihat muka yang lain dan mendengar dengan telinga sendiri suaranya. ${ }^{10}$ Wawancara dilakukan secara terbuka (openended) untuk menggali pengamatan terhadap subyek penelitian perihalImplementasi Strategi Pembelajaran Program Studi Pendidikan Bahasa Arab IAIN Samarinda dan Wawancara dilakukan pada waktu dan konteks yang relatif tepat untuk mendapatkan data akurat serta mendukung data penelitian ini.Metode wawancara yang dilakukan peneliti adalah wawancara yang berstruktur, dan tidak berstruktur. Dalam wawancara berstruktur, peneliti sebelum bertanya kepada subyek penelitian terlebih dahulu menyiapkan konsep pertanyaan yang relatif mudah difahami. Wawancara yang tidak berstruktur terbagi 2 (dua) yaitu terarah dan tidak terarah, Sedangkan wawancara tidak terarah diharapkan dapat mengungkap berbagai hal yang berkaitan dengan rumusan permasalahan yang ada pada fokus penelitian ini.

d) TahapanPenelitian

Penelitianinidilakukanmelaluibeberapatahapan.Tahapan-tahapan tersebutmeliputi:tahappra-lapangan,tahappekerjaanlapangan,dantahap analisisdatahinggatahappelaporanhasilpenelitian. ${ }^{11}$ Adapunpenjelasan berbagaitahaptersebutsebagaiberikut:

1) TahapPra-lapangan

Padatahappra-lapanganini,penelitimulaidarimengajukanjudul kepada koordinator LP2M IAIN Samarinda, kemudianpenelitimembuatproposalpenelitianyangjudulnyasudah disetujui,dilanjutkeujianproposal,SelanjutnyaPenelitimempersiapkansu

${ }^{10}$ Arief Furqan, Pengantar Penelitian Dalam Pendidikan (Surabaya: Usaha Nasional, 1982), h. 192.

${ }^{11}$ Lexy j.Moleong, Metedologi penelitian kualitatif, Bandung, (PT Remaja rosdakarya, 2009), h. 127.

Jurnal Ilmiah Al QALAM, Vol. 12, No. 2, Juli-Desember 2018 
Edy Murdani Z: Implementasi Strategi Pembelajaran Prodi Pendidikan Bahasa Arab IAIN Samarinda 2018

ratijinpenelitian

dankebutuhanpenelitianlainnyasebelummemasukilokasipenelitian danjugapenelitiselalumemantauperkembanganlokasipenelitian sebagaibentukstudipendahuluhan.

2) TahapPekerjaanLapangan

Setelahmendapatijin,peneliti kemudianmempersiapkandiriuntukmemasukilokasipenelitiantersebut demimendapatkaninformasisebanyak-banyaknyadalampengumpulan data.Penelititerlebihdahulumenjalinkeakrabandenganinformandalam berbagaiaktivitas,agarpenelitiditerimadenganbaikdanlebihleluasa dalammemperolehdatayangdiharapkangunamenjawabfokus penelitian.

3) TahapAnalisisData

Setelah data diperoleh dari dokumentasi, pengamatan dan wawancara di lapangan, analisis data dimulai dengan pengolahan data mentah. Mengolah data berati membuat ringkasan berdasarkan data mentah hasil pengumpulan data ${ }^{12}$, kemudian $^{2}$ menelaahnya,membagi,danmenemukanmaknadariapayangtelah diteliti.Untukselanjutnya,hasilpenelitiandilaporkandandisusunsecara sistematismenjadilaporanpenelitian.

Dariuraiandiatas,secarajelastahap-tahappenelitiandidalam penelitianinidapatdigambarkansebagaiberikut:

Langkahpertama:identifikasimasalah.Didalampenelitianini penelitimengidentifikasiberbagaimasalahyangmunculterkait implementas Strategi pembelajaranbahasaArabdi Prodi Pendidikan Bahasa Arab IAIN Samarinda, Langkahkedua:fokuspenelitian.Sejumlahmasalahyangsudah diidentifikasimelaluiprosesreduksiakandikajididalamfokusmasalah.

Langkahketiga:fokusmasalah.Didalamfokusmasalah, masalah-

${ }^{12}$ Lexy j, Moloeng, Metode Penelitian.., h. 248.

Jurnal Ilmiah Al QALAM, Vol. 12, No. 2, Juli-Desember 2018 
Edy Murdani Z: Implementasi Strategi Pembelajaran Prodi Pendidikan Bahasa Arab IAIN Samarinda 2018

masalahyangdipaparkanadalahmasalah-masalahyangsudah ditentukandalamfokuspenelitian.

Langkahkeempat:pengumpulandata.Pengumpulandatadi dalampenelitianinidilakukandenganobservasipartisipatif(participanto bservation), wawancaramendalam(indeptinterview),dandokumentasi (documentation).

Langkahkelima:pengolahandanpemaknaandata.Pengolahan danpemaknaandatadidalampenelitianinidilakukansetelahdata-data hasi observasipartisipatif (participant observation),wawancara mendalam(indeptinterview), dandokumentasi(documentation)yang penelitidapatkandiProdi Pendidikan Bahasa Arab IAIN Samarinda.

Langkahkeenam:pengkajianteori,didalampenelitiankualitatif teoriberfungsisebagaialatdansebagaitujuan.Teorisebagaialat dimaksudkanbahwadenganteoriyangadapenelitidapatmelengkapidan menyediakanketeranganterhadapfenomenayangditemui.Teorisebagai tujuanmengandungmaknabahwatemuanpenelitiandapatdijadikan teoribaru,menguatkanataumembantahteoriyangsudahada.

Langkahketujuh:pelaporanhasilpenelitian.Laporanhasil penelitiandidalampenelitianinidilaksanakanketikasemuadata-data darihasilobservasipartisipatif(participantobservation), wawancara mendalam(indeptinterview), dandokumentasi(documentation)sudah terkumpulsemua.Setelahdataterkumpulsemua,datatersebutdireduksi. Langkahselanjutnyasetelahdatadireduksiadalahmelakukan pengecekankeabsahandata melalui keterpercayaan, keteralihan, dan ketergantungan yang telah dipaparkan sebelumnya.

\section{Pembahasan}

Padatema

ini, peneliti akanmemapaparkanhasiltemuanpenelitiandananalisisdata yang telah dilakukanuntukmenyusunkonsepyang 
Edy Murdani Z: Implementasi Strategi Pembelajaran Prodi Pendidikan Bahasa Arab IAIN Samarinda 2018

didasarkanpadainformasiempirisyangdiperolehselamapenelitiandilapangan.

Padabagianiniakandiuraikanmengenai implementasi strategi

pembelajaranpembelajaranbahasaArab beserta

teknikpembelajaranbahasaArabdalambahasaArabdiProdi Pendidikan Bahasa

Arab IAIN. Dosen Prodi Pendidikan Bahasa Arab dalam hal inimenggunakansuatuperhitungan/persiapantentangkondisidansituasidimanaa garprosestersebutdapatberlangsungdalamjangkapanjang.Denganperhitungante rsebut,makaprosespembelajaranbahasaArabdiProdi Pendidikan Bahasa Arab IAIN

Samarindaakanlebihterarahkepadatujuanyanghendakdicapai,karenasegalasesu atunyatelahdirencanakansecaramatang serta menyiapkan beberapa latihan dan evaluasi sebagaimana yang dikatakan Ahmad Fuad Ilyan ${ }^{13}$ sehingga menjadi suatu kesatuan yang akan diajarkn kepada mahasiswa.Maka dari itu, pembelajarandiProdi Pendidikan Bahasa Arab IAIN Samarindamenggunakanberbagai macam strategiyangmenyangkutpadamasalahbagaimanamelaksanakanproses pembelajaranterhadapsasaranpembelajarandenganmelihatsituasidan kondisiyangadadanbagaimanaagardalamprosestersebuttidakterdapat hambatansertagangguanbaikinternalmaupuneksternalyangmenyangkut kelembagaanataulingkungansekitarnya.

Strategipembelajaranharusmengandungpenjelasantentangmetode prosedurdantehnikyangdigunakanadapun selamaproses pembelajaran berlangsung.Denganperkataanlain,strategipembelajaranmengandungarti yanglebihluasdarimetodedantehnik. Artinyametodedantehnik pembelajaranmerupakanbagiandaristrategipembelajaran.Olehsebab itulahdalamsebuahstrategipembelajaranselaluterikatdenganyang

13 أحمدفؤ ادحمدعليان , المهار اتاللغويةماهيتهاوطر ائقتدريسهار المسلم ,الرياض, ص11 
Edy Murdani Z: Implementasi Strategi Pembelajaran Prodi Pendidikan Bahasa Arab IAIN Samarinda 2018

namanyametodepembelajaran ,teknik pembelajarandanevaluasi pembelajaran. ${ }^{14}$

Istilahstrategi,metode, dantehnikseringdigunakansecarabergantian walaupunpadadasarnyaistilah-istilahtersebutmemilikiperbedaansatu denganyanglain.Tehnikpembelajaranseringkalidisamakandenganmetode pembelajaran.Tehnikpembelajaranadalahapayangsesungguhnyaterjadidi dalamkelasdanmerupakanpelaksanaandarimetodeyangsifatnya implementatif. ${ }^{15}$ StrategipembelajaranyangdigunakanProdi Pendidikan Bahasa Arab IAIN Samarindabermacam macamdisesusaikandenganketerampilanbahasaArabapayanghendak dicapai,metodepembelajarandiProdi Pendidikan Bahasa Arab IAIN Samarindaadalahsuatucarayang digunakanuntukmenyampaikanmaterikepadamahasiwasedangkanmenurut teorimetodepembelajaranadalahcarakerjayangbersistemuntuk memudahkanpelaksanaansuatukegiatangunamencapaitujuanyang ditemukan.Strategi pembelajaranlebihbersifatprosedural,yaituberisi tahapantertentu,sedangkantehnikadalahcarayangdigunakanyangbersifat implementatif. Hubunganantarastrategi,tujuandanmetodepembelajarandapat digambarkansebagaisuatukesatuansistemyangbertitiktolakdaripenentuan tujuanpembelajaran,pemilihanstrategipembelajaran,danperumusantujuan, yangkemudiandiimplementasikankedalamberbagaimetodeyangrelevan selamaprosespembelajaranberlangsung. ${ }^{16}$

Penjelasandiatas, dapatdianalisisbahwadalampembelajaranitu memerlukanstrategi,metode,dantehnikpembelajaran keterkaitanantara ketiganyaitudapatdigambarkansebagaisuatukeadaansistemyangbertitik tolakdaripenentuantujuanbelajar.Jika dilihatketiganyatersebuthampir

\footnotetext{
${ }^{14}$ WinaSanjaya,StrategiPembelajaranBerorientasiStandarProsesPendidikan (Jakarta: Kencana,2009), h.210.

${ }^{15}$ AzharArsyad,BahasaArabdanMetodePengajarannya(Yogyakarta:Pustaka Pelajar,2010), h. 19.

${ }^{16}$ HamzahB.Uno,ModelPembelajaran(Jakarta:SinarGrafika,2008), h.13.
}

Jurnal Ilmiah Al QALAM, Vol. 12, No. 2, Juli-Desember 2018 
Edy Murdani Z: Implementasi Strategi Pembelajaran Prodi Pendidikan Bahasa Arab IAIN Samarinda 2018

samanamunsebenarnnyamemilikiperbedaantersendiri.bila metode

merupakancarauntukmelakukansuatupembelajaranagarlebihtepatdan sesuaisituasipesertadidik,makaperlujugadiaturketepatanpenggunaan metode,tehnikdanstrategipenerapanmetode.Apabila sajametodeitu sebenarnyasudahbaiktetapikarenakurangtepatnyapenerapanmetodemaka hasilpembelajarannyapunakankurangmaksimal.

Lainhalnyadenganstrategi.Strategidisiniberfungsimengatur ketepatanpenggunaanberbagaimetodedalampembelajarantersebut.Jadi seorangpendidikdisampingharusmenguasaiberbagaimetodepembelajaran diajugaharusmenguasaitehnikdanstrategiagarmetodeyangtelah dikuasainyaitubisaditerapkandengantepatdalamsuatupembelajaran. Karenabegitupentingnyapembelajaranbagi peserta didik dalam kehidupannyamakamenjadipentingpulalahagarprosespembelajaranitu bisaberjalandenganlancar,efektif,danefisien. ${ }^{17}$

Prodi Pendidikan Bahasa Arab IAIN

SamarindamenerapkanstrategidalampembelajaranbahasaArab, karenamerekamengetahuibahwadalampembelajaranbahasaArabada unsurunsur bahasa dan4 keterampilanyangharusdikuasaiyaituketerampilanmendengar(istimak), berbicara(takallum),membaca(qira'ah)danmenulis(kitabah),kesemuanya tersebuttidakbisadicapaihanyadengan 1 macam s t r a t e g i / metode pembelajaranbahasaArabsaja.Namunharusdipilihstrategiyangtepatuntuk keterampilanyangtepat,Olehsebabitulah pengampu mata kuliah Prodi Pendidikan Bahasa Arab IAIN Samarindamenerapkanbeberapa strategi pembelajaranbahasaArabyangberbedayangdigunakanuntukmencapai penguasaan unsur bahasa dan keempatketerampilanyangada(maharah)yaituketerampilan mendengar(istimak), berbicara(takallum), membaca(qira'ah)danmenulis

\footnotetext{
${ }^{17}$ WinaSanjaya,StrategiPembelajaranBerorientasiStandarProsesPendidikan (Jakarta: Kencana,2009),h.217.
}

Jurnal Ilmiah Al QALAM, Vol. 12, No. 2, Juli-Desember 2018 
Edy Murdani Z: Implementasi Strategi Pembelajaran Prodi Pendidikan Bahasa Arab IAIN Samarinda 2018

(kitabah). Strategi Pembelajaranyangdigunakankebanyakan sama,untuk pembelajaran unsur bahasa, seperti Nahwu, Shorof, dan Tarjamah, pengampu menggunakan metode/strategi qowaid dan tarjamah yang didukung dengan metode hafalan,pengampu dalam hal ini, menitik beratkan pada analisis tata bahasa agar memahami bahasa dengan baik sebagaimana yang dikemukakan oleh Sri Utari, inti kegiatan belajar bahasa asing adalah menganalisa tata bahasa, menulis kalimat dan menghapalkan kosa kata sebagai dasar transformasinya kedalam bahasa yang digunakan sehari hari. ${ }^{18}$

Adapun dengan pembelajaran keterampilan, untuk keterampilanmendengar(istimak) pengampu menggunakan strategi cooperative learning dan permainan strategi ini juga ditunjang dengan fasilitas Laboratorium bahasa yang terjadwal digunakan oleh mahasiswa dalam materi kuliah istima,danketerampilanbicara (takallum)pengampu matakuliah menggunakanstrategi active learning, strategi ini menuntunpembelajaran

bahasaArablangsungyangmanamahasiwadimintauntukberbahasa

Arabketikaberkomunikasidengantemannyatanpaadanyabahasaibu, memang dalam latihan berbicara Muhammad Kamil melihat ada tiga hal penting yang harus dimiliki yaitu ujaran, kosakata, serta bagaimana kaidah penggunaanya ${ }^{19}$ jika hal ini terpenuhi maka akan baik hasilnya dan metode yang sering ditemukan di pondok-pondok pesantren adalah metode mubasyarah yang sifatnya langsungdanintensifdalamkomunikasi ${ }^{20}$ dan ini memang terlihat selaras, hal ini berbeda tentunya jika ini diterapkan pada pembelajaran unsurbahasadalammetodeinitidak diperhatikan,sebabtekananintinyaadalahbagaimanaagarpelajarpandai

\footnotetext{
${ }^{18}$ SriUtariSubyaktiNababan,MetodologiPengajaranBahasa(Jakarta:Gramedi aPustakaUtama,1993), h. 11.

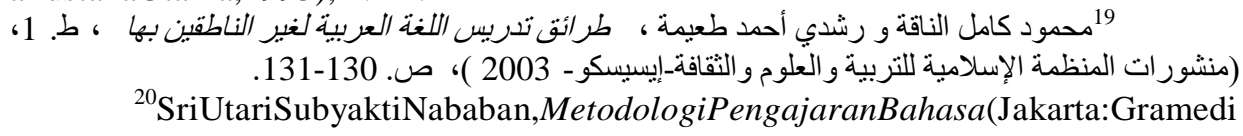

${ }^{20}$ SriUtariSubyaktiNababan,MetodologiPengajaranBahasa(Jakarta:Gramedi aPustakaUtama,1993),h.15.
} 
Edy Murdani Z: Implementasi Strategi Pembelajaran Prodi Pendidikan Bahasa Arab IAIN Samarinda 2018

menggunakanbahasaasingyangdipelajaribukanpandaitatabahasaasing yangdipelajari.Tatabahasahanyadiberikanmelaluisituasi(kontekstual)dan dilakukansecaralisan,bukandengancaramenghapalkaidahkaidah dan jikadiperlukanevaluasiakhirberupapertanyaan pertanyaandialogyangharusdijawabolehpelajarsebagaimanapolapola dialogdiatas.Pelaksanaannyabisasajasecaraindividualataukelompok sesuaidengansituasidankondisi.Jikatidakmemungkinkankarenawaktu misalnyadosen dapatmenyajikanberupatugas. ${ }^{21}$

UntukketerampilanmembacaProdi Pendidikan Bahasa Arab IAIN Samarindamenggunakan strategi membaca teksArablangsung baik shomitah maupun jahriyahuntukmelatihketerampilanmahasiwadalammembacateks Arabdanmengartikannya,sebagaimanatujuanutamadarimetodeqira' ah adalahmenanamkankemampuanmembacateksteksbahasaasingdengan mudahtanpaharusmenerjemahkanbaiksecaralisanmaupuntuliskedalam bahasapelajar,tetapilangsungmencernaisiyangterkandungolehteks bahasaasing. ${ }^{22}$ MenurutSyaifulgalamembacamempunyaimaknayanglebih luasyaituprosesmembaca,menelitidanmemahamisegalasesuatutanpa batas. ${ }^{23}$ membacamufrodatyangbenarkemudianakan diikutiolehmahasiwadandiulangsebanyak3sampai5kalisampaidirasamahasiwas udahmampumengucapkannyasecarabenar,dengandemikiankemampuan membaca(qira'ah)mahasiwaakansemakinmeningkatmendekatibacaanpenutur asli,halinisebagaimanakonsepdasardarimetodeqira'ahyaitumelatih siswaagarmampumengucakanbahasasepertipenuturaslinya,dansasaran utamametodeqira' ahadalahmemperolehinformasiilmiahsebanyak

\footnotetext{
${ }^{21}$ AhmadFuadEfendi,MetodologiPengajaranBahasaArab(Malang:Misykat,2 005), h.181.

${ }^{22}$ AcepHermawan,MetodologiPembelajaranBahasaArab(Bandung:PT.Rem ajaRosdakarya), h.194. h. 134 .

${ }^{23}$ SyaifulSagala,KonsepdanMaknaPembelajaran(Bandung:Alfabeta,2005),
}

Jurnal Ilmiah Al QALAM, Vol. 12, No. 2, Juli-Desember 2018 
Edy Murdani Z: Implementasi Strategi Pembelajaran Prodi Pendidikan Bahasa Arab IAIN Samarinda 2018

banyaknyadariteksteksilmiah.Salahsatukegiatanpentinguntuk memperolehinformasiituadalahmembaca,mulaidarimembacanyaring sampaipemahaman. ${ }^{24}$

Secaragarisbesarlangkahlangkahpenggunaaanmetodeqira'ahyang digunakandiProdi Pendidikan Bahasa Arab IAIN Samarindadiatashampirsamadenganlangkahlangkahpenggunaaanmetode qira'ahsecarapembahasan ilmiah yang ada dibuku metode pembelajaran.

SedangkanstrategipembelajaranyangdigunakanolehProdi Pendidikan $\begin{array}{llll}\text { Bahasa } & \text { Arab } & \text { IAIN } & \text { Samarindauntuk }\end{array}$ keterampilanmenulisnyaadalahimlakmenggunakanstrategi drill.Untukimlakmahasiwadiajaricaramenuliskatakatadankalimatkalimat dalambahasaArabdenganbaikdanbenarkarenabelumtentuketikamahasiwa bisamelafalkanmufrodattersebutataumembacanyadenganbenarmahasiwabisa menulisnyadenganbenarpula,makadariituperlusuatumetodekhusus untukketerampilanmenulis,tujuan dari pembelajaran kitabahadalah melatihmahasiwaagarmenguasaiketerampilanmenulis(al-imla'), mengarang (al-insya ')dankaligrafi( $a l$ -

khath). ${ }^{25}$ Imlakadalahkategorimenulisyangmenekankanrupa/posturhuruf dalammembentukkata-katadankalimatataubisadiartikanmenuliskan hurufhurufsesuaiposisinyadenganbenardalamkata-katauntukmenjaga terjadinyakesalahanmakna.Mengarang(al-insya' $)$ adalahkategorimenulis yangberorientasikepadapengekspresianpokokpikiranberupaide,pesan, perasaandansebagainyakedalambahasatulisan,bukanvisualisasibentuk ataurupahurup,kata,ataukalimatsaja.Makawawasandanpengalaman pengarangsudahmulaidilibatkanMenuliskarangan. adapun PenggunaanteknikpembelajaranbahasaArabdiProdi Pendidikan Bahasa Arab IAIN Samarindaadalahbentukimplikasipembelajaranyangadadikelas,

\footnotetext{
${ }^{24}$ AzharArsyad,BahasaArabdanMetodePengajaran...h. 89.

${ }^{25}$ MuhammadAliAlKhuli,StrategiPembelajaranBahasaArab(Yogyakarta:Ba sanPublishing), h. 151.
}

Jurnal Ilmiah Al QALAM, Vol. 12, No. 2, Juli-Desember 2018 
Edy Murdani Z: Implementasi Strategi Pembelajaran Prodi Pendidikan Bahasa Arab IAIN Samarinda 2018

Istilahteknikdalampembelajarandidefinisikandengancaracaradanalatyangdigunakanolehgurudalamrangkamencapaisuatutujuan,langsun gdalampelaksanaanpelajaranpadawaktuitu.Haltersebutsebagaimanadijelaskan olehAzharArsyad,bahwateknikyaituapayangsesungguhnyaterjadididalamkelas danmerupakanpelaksanaandarimetodeyangsifatnyaimplementatif. ${ }^{26}$

Teknikdalampembelajaranmerupakanpenjelasandanpenjabaransuatum etodepembelajaran,makasudahbarangtentudalampembelajaranbersifattaktis,da ncenderungbernuansasiasat.Jaditehnikmerupakan keterampilandanseni(kiat)untukmelaksanakanlangkah-langkahyang sistematikdalammelakukansuatukegiatanyanglebihluasataumetode. Misalkan,penggunaanmetodeceramahpadakelasdenganjumlah siswayangrelatifbanyakmembutuhkantekniktersendiri,yangtentunya secarateknisakanberbedadenganpenggunaanmetodeceramahpadakelas yangjumlahsiswanyaterbatas.Demikianpula,denganpenggunaanmetode diskusi,perludigunakanteknikyangberbedapadakelasyangsiswanya tergolongaktifdengankelasyangsiswanyatergolongpasif.Dalamhal teknikpembelajaranyangdigunakandalammetodeqiro'ahdiProdi Pendidikan Bahasa Arab IAIN Samarindauntukketerampilanmembacaadalahteknikmembacanyaringyaitumah asiwadiberisebuahteksArabataudialogArab.SetelahdiberibacaanArab, mahasiwadiajakbersamasamamembacanyasambildiarahkanolehpengampu bagaimanabacaanyangbenar.Sesuaidengantujuanutamadarimetodeqira 'ahyait umenanamkankemampuanmembacateksteksbahasaasing denganmudahtanpaharusmenerjemahkanbaiksecaralisanmaupuntuliske dalambahasapelajar,tapilangsungmencernaisiyangterkandungolehteks bahasaasing. ${ }^{27}$

Sedangkandalammetodekitabahuntukketerampilanmenulis(kitabah) teknikpembelajaranyangdigunakanProdi Pendidikan Bahasa Arab IAIN

\footnotetext{
${ }^{26}$ AzharArsyad,BahasaArabdanMetodePengajarannya..., h. 48.

${ }^{27}$ AzharArsyad,BahasaArab...h. 194.
} 
Edy Murdani Z: Implementasi Strategi Pembelajaran Prodi Pendidikan Bahasa Arab IAIN Samarinda 2018

\section{Samarindaadalahteknikmengarang}

terpimpin.untukteknikmengarangterpimpin(al-insyakal-muwajjah)mahasiwa disuruhmembuatsebuahteksArabsendiriyangnantiakandikoreksiolehpengampu ,haltersebutdilakukanuntukmelatih kemampuanmengarangmahasiwa(insyak),sepertidefinisidariteknikmengarang terpimpin(al-insyakal-muwajjah)yaitumembuatkalimatatauparagraf sederhanadenganbimbingantertentuberupapengarahan. ${ }^{28}$

Dalam implementasi yang telah dipaparkan sebelumnya, para pengampu melihat, bahwa jam perkuliahan yang ada dalam sistem akademik yang telah dijadwal tidak membemberikan waktu yang maksimal khususnya pada pengkondisian sebaran matakuliah, hal itu dikarenakan bahwa, umumnya materi pekuliahan dalam bahasa Arab hanya unsur bahasa dan keterampilan saja yang mendapat fokus kontent bahasa Arab, adapun yang lain, seperti materi agama islam, dan materi metedologi masih menggunakan bahasa indonesia, pada pembelajaran yang integral sangat diperlukan, sebagaimana yang dikatakan oleh nur hadi ${ }^{29}$ bahwa pembelajaran bahasa kedua hendaknya dituangkan dalam materi-materi belajar, buku, komunikasi. Selanjutnya, walaupun secara umum, sifat dari implementasi ini adalah normatif ${ }^{30}$, yang berarti bahwa hal yang telah dilakukan oleh pengampu adalah bagian dari tugas dan fungsi dosen, sebagai mana arti kata tersebut namun temuan peneliti yang agak berbeda adalah tentang penggunaan strategi oleh dosen, didapatkan bahwa sedikit berbeda dari teori yang umum yang ditemukan di buku-buku yang membahas tentang strategi ataupun metode pembelajaran bahasa, sebagai contoh bahwa untuk mempelajari keterampilan berbicara, pengajar bahasa biasanya menggunakan direct method (thoriqoh mubasyaroh ) namun, dalam penelitan ditemukan hal lain, begitu pula, dalam pembelajaran keterampilan istima. Dalam perjalannya banyak yang menjadi penghambat dari strategi

\footnotetext{
${ }^{28}$ AcepHermawan,MetodologiPembelajaran ...h. 164.

${ }^{29}$ Nur Hadi dan Royhan, Dimensi-Dimensi Dalam Belajar Bahasa Kedua, (Bandung: Sinar Baru, 1982 ), h. 210.

${ }^{30}$ Kamus besar bahasa indonesia online, di akses pada 8 juni 2018.
}

Jurnal Ilmiah Al QALAM, Vol. 12, No. 2, Juli-Desember 2018 
Edy Murdani Z: Implementasi Strategi Pembelajaran Prodi Pendidikan Bahasa Arab IAIN Samarinda 2018

tersebut, para dosen sepakat bahwa tingkat kognitif yang berbeda karna latar belakang pendidikan yang berbeda sangat berpengaruh besar terhadap kelancaran implementasi tersebut yang berbanding lurus dengan belum dialihbahasakannya semua materi dalam prodi bahasa Arab karena berbagai macam pertimbangan.

Jurnal Ilmiah Al QALAM, Vol. 12, No. 2, Juli-Desember 2018 
Edy Murdani Z: Implementasi Strategi Pembelajaran Prodi Pendidikan Bahasa Arab IAIN Samarinda 2018

\section{Simpulan}

Implementasi strategi pembelajaran pada prodi pendidikan bahasa Arab IAIN Samarinda berjalan dengan baik yang sifatnya normatif implementatif, hal itu ditunjukan dengan pelaksanaan pembelajaran yang telah dilakukan oleh pengampu mata kuliah berjalan sesuai fungsinya, semisal menyiapkan silabus dan perangkat pembelajaran, menggunakan strategi dan tehnik dalam pengajarannya, dan mengadakan evaluasi pada akhir perkuliahan.

Strategi yang digunakan dalam pembelajaran pada prodi pendidikan bahasa Arab IAIN Samarinda adalah active learning untuk keterampilan berbicara, cooperative learning untuk keterampilan mendengar, qowaid wa tarjamah untuk pembelajaran unsur bahasa baik nahwu, shorof dan tarjamah, dan untuk keterampilan membaca adalah qiraah shomitah dan jahriyah, drill dan awlawiyat untuk untuk keterampilan menulis.

Faktor yang mendukung implementasi tersebut adalah a. Pengampu menyiapkan perangkat pembelajaran pada setiap pertemuan b. Pengampu menentukan strategi dan tehnik yang tepat dalam menyesuaikan materi ajar $\mathrm{c}$. Tersedianya media belajar dengan baik.

Faktor yang penghambat dari implementasi tersebut adalah pembelajaran tersebut adalah a. Kualifikasi mahasiswa, sehingga penerapan strategi harus benar-benar tepat sasaran dan menyesuaikan tingkat kognitif mahasiswa b. Sebaran mata kuliah belum semua berbahasa Arab, sehingga lingkungan akademik berbahasa susah diterapkan secara maksimal. 
Edy Murdani Z: Implementasi Strategi Pembelajaran Prodi Pendidikan Bahasa Arab IAIN Samarinda 2018

\section{Daftar Pustaka}

Arikunto, Suharsimi. Prosedur Penelitian Suatu Pendekatan Praktik. Jakarta: Rineka Cipta, 1993.

Arsyad, Azhar. Bahasa Arab dan Metode Pengajarannya. Yogyakarta: Pustaka Pelajar, 2010.

Efendi, Ahmad Fuad. Metodologi Pengajaran Bahasa Arab. Malang: Misykat,2005.

Furqan, Arief. Pengantar Penelitian Dalam Pendidikan. Surabaya: Usaha Nasional, 1982.

Hadi, Nur dan Royhan, dimensi-dimensi dalam belajar bahasa kedua. Badung: Sinar Baru , 1982.

Hadi, Sutrisno. Metodologi Research. Yogyakarta: Fak. Psikologi UGM, 1985.

Hermawan, Acep. Metodologi Pembelajaran Bahasa Arab. Bandung: PT.Remaja Rosdakarya.

Husin, Husin, dan Hatmiati Hatmiati. "Budaya Dalam Penerjemahan Bahasa." Al-Mi'yar, 2, 1 (2018).

Khuli, Muhammad Ali. Strategi Pembelajaran Bahasa Arab. Yogyakarta:Basan Publishing, tt.

Moleong, Lexy j. Metedologi penelitian kualitatif. Bandung: PT Remaja Rosdakarya, 2009.

Muhajir, As'aril. Psikologi Belajar Bahasa Arab. Jakarta: BinaIlmu,2004.

Nababan, Sri Utari Subyakti. Metodologi Pengajaran Bahasa. Jakarta: Gramedia Pustaka Utama,1993.

Narbuko, Cholid, Abu Ahmadi. Metodologi Penelitian. Jakarta: PT Bumi Aksara,2003.

Sagala, Syaiful. Konsep dan Makna Pembelajaran. Bandung: Alfabeta,2005.

Sanjaya, Wina. Strategi Pembelajaran Berorientasi Standar Proses Pendidikan. Jakarta: Kencana,2009.

Uno, HamzahB. Model Pembelajaran. Jakarta:SinarGrafika,2008.

W.Surakhmad. Pengantar Penelitian Ilmiah: DasarMetode Teknik. Bandung: Tarsito,1990.

أحمدفؤ ادعليان المهار اتاللغويةماهيتهاوطر ائقتدريسه (دار المسلم ,الرياض 1992 ) )

حسن شحاتة , تعليم اللغة العربية بين النطرية و التطبيق( دار المصرية البنانية 1993)

Jurnal Ilmiah Al QALAM, Vol. 12, No. 2, Juli-Desember 2018 
Edy Murdani Z: Implementasi Strategi Pembelajaran Prodi Pendidikan Bahasa Arab IAIN Samarinda 2018

محمود كامل الناقة و رشدي أحمد طعيمة ، طرائق تدربيس اللغة العربية لغبر الناطقبن بها ، ط. 1.

(منشور ات المنظمة الإسلامية للتربية و العلوم و الثقافة-إيسيسكو - 2003 )،

Jurnal Ilmiah Al QALAM, Vol. 12, No. 2, Juli-Desember 2018 